\title{
Innovative Development of Building Materials Industry of the Region Based on the Cluster Approach
}

\author{
Asiiat Mottaeva ${ }^{1, *}$ Alexander Zheltenkov ${ }^{2}$, Irina Stukanova ${ }^{2}$, Sergei Ryabichenko ${ }^{2}$, and \\ Sophia Zhuk ${ }^{3}$ \\ ${ }^{1}$ Moscow State University of Civil Engineering, 129337 Yaroslavskoe sh. 26, Moscow, Russia \\ ${ }^{2}$ Moscow regional state University ,129125 Radio str. 10, Moscow, Russia \\ ${ }^{3}$ Financial University under the government of the Russian Federation, 125993 Leningrad pr. 49, \\ Moscow, Russia
}

\begin{abstract}
The article discusses issues of innovative development of building materials industry of the region based on the cluster approach. Determined the significance of regional cluster development of the industry of construction materials as the effective implementation of the innovative breakthrough of the region as an important part of strategies for strengthening innovation activities may be to support the formation and development of cluster structures. Analyses the current situation with innovation in the building materials industry of the region based on the cluster approach. In the course of the study revealed a direct correlation between involvement in innovative activities on a cluster basis, and the level of development of industry of construction materials. The conducted research allowed identifying the factors that determine the innovation process, systematization and classification which determine the sustainable functioning of the building materials industry in the period of active innovation. The proposed grouping of innovations for the construction industry taking into account industry-specific characteristics that reflect modern trends of scientific and technological progress in construction. Significance of the study lies in the fact that the proposals and practical recommendations can be used in the formation mechanism of innovative development of building materials industry and the overall regional construction complex of Russian regions by creating clusters of construction.
\end{abstract}

\section{Introduction}

The development of innovation and leadership in the global economy is the trend of development of science and technology policy, and this process does not depend on the

\footnotetext{
* Corresponding author: doptaganka@yandex.ru
} 
type of state or of a political regime. However, the level of innovation in selected countries and regions is uneven.

As a rule, it depends on the willingness of a particular State to organize the innovation process, to manage this process and regulate the relations arising in the sphere of innovations. In this context, it becomes relevant to use strategic approaches to innovation management, allowing purposefully lead the process. This strategic management of innovative activity should be carried out at the level of the Executive Innovation (Company), and the meso and macro levels - regional level, the industry, and the state as a whole.

A key factor in the success of innovation in this situation, is the ability to link listed in the single-level strategy. In this paper, it is possible to implement it with the help of the new Russian economy forms of organization of economic subjects, science, infrastructure and state - clusters.

Building materials industry is a major area of the economy, including more than 15 branches and forming the basis of the material and technical base of construction, the cost of building materials is the main section of the building complex costs.

Meanwhile, the gap in the innovative development of the industry of construction materials leads to a stagnation of the entire building complex, both because of the use of obsolete materials and technologies, as well as due to the high cost of their purchase.

Theoretical and methodological basis of studies of scientific approaches to the formation of an innovation cluster in the building materials industry served as the scientific works of domestic and foreign authors. The basis of the innovation theory is easy foreign scientists: J. Schumpeter [3] B. Twiss [5], B. Santo [4]. Strategic management of innovative activity also engaged Drucker [2], I. Ansoff [1] R.

A significant influence on the development of the theory of clusters had M. Porter [8], C. Ketels [6] O. Solvell [7], Solène Goy, Donal Finn [9] Frank J. Kaltsonetti, Diane M. Miller, Neil Reed [10], Fundeanu Daniela Doina, Cosmin Sandu Badele [11] M. Khairullina [12]. An important role in the development of a building complex and building materials industries LN Asaul [13], AV Voronin [14], IM Greenberg, [15] M. Casas [16] S. Kolyada [17] and etc.

\section{Methodology}

At all times the status of the construction industry characterized the level of well-being and opportunities of development. In addition, the building complex, which includes the production of construction materials, plays a leading role in the economy of any region, and its condition is one of the indicators of economic and technological development.

Despite the fact that the construction industry is quite conservative, the new conditions of the market economy, focused on the use of new technologies and resursos-beregayuschih materials led her to certain changes in investment-making insulating complex with intensive use of innovative programs. The need for innovation is dictated primarily demand to reduce the cost of construction and operation of housing, as well - reducing construction time and improve the quality of living. [18].

In this regard, the main objectives for the construction materials industry enterprises are: the implementation of programs for the modernization of production, increase in the volume of production and sales, improving energy efficiency requirements and resources as the production processes and the products themselves.

The most popular have become the technology and construction materials related to energy saving, as now in Russia and around the world, energy efficiency is a key requirement of modern construction. One of the major obstacles standing in the way of 
implementation of many innovations is the problem of ensuring the effective interaction between stakeholders in the innovation process.

This problem is particularly acute in the early stages of innovation. It is at these stages of innovation requires investments at the maximum level of uncertainty.

The uncertainty arises from the fact that in the early stages there is no evidence of promising innovations, in addition, innovators can be difficult to outline the range of potentially interested in the subjects of innovation.

Difficulties in co-innovation participants in the early stages may also arise due to the fact that different stakeholders have different opinions innovation, considering them from a different perspective.

Thus, the scope of innovation experts note that the authors of innovations often overestimate their capacity, not taking into account the existing substitutes, inertia in consumer behavior as well as other psychological aspects of the adoption of new products by the market. When communicating with investors, who are interested primarily commercial potential of innovation, the authors often delve into the technical details, and the commercial component is characterized by superficial or overly optimistic.

At the same time, it is often the quality of the interaction between the participants of innovation depends on whether it will be implemented, in what circumstances and in what time frame. The effectiveness of innovative development of building materials industry is caused, linking the main factors:

- The potential of science, new ideas, discoveries and developments;

- Structure and production requirements;

- The resource base of innovative development;

- The availability of an effective management system that is adequate to the requirements of the time. [26]

These factors must interact so that the potential of science is constantly ahead of the needs of innovative enterprise development.

On this basis, by co-measuring with the resource potential in the planned period necessary to carry out selection of the most effective programs and activities of innovative development.

The main components that meet the specified requirements are available at the enterprise of scientific and technical base; innovative infrastructure of the region, contributing to the implementation of innovative development activities; degree of innovation susceptibility staff, its professional and educational level; opportunities and conditions for the implementation of programs and projects of innovation development, reflecting the interaction of the company in this aspect with other companies and organizations directly or indirectly interested in the development of the system [25].

Based on the foregoing appears to be the mechanism of formation of innovation potential of construction companies (Fig.1) 


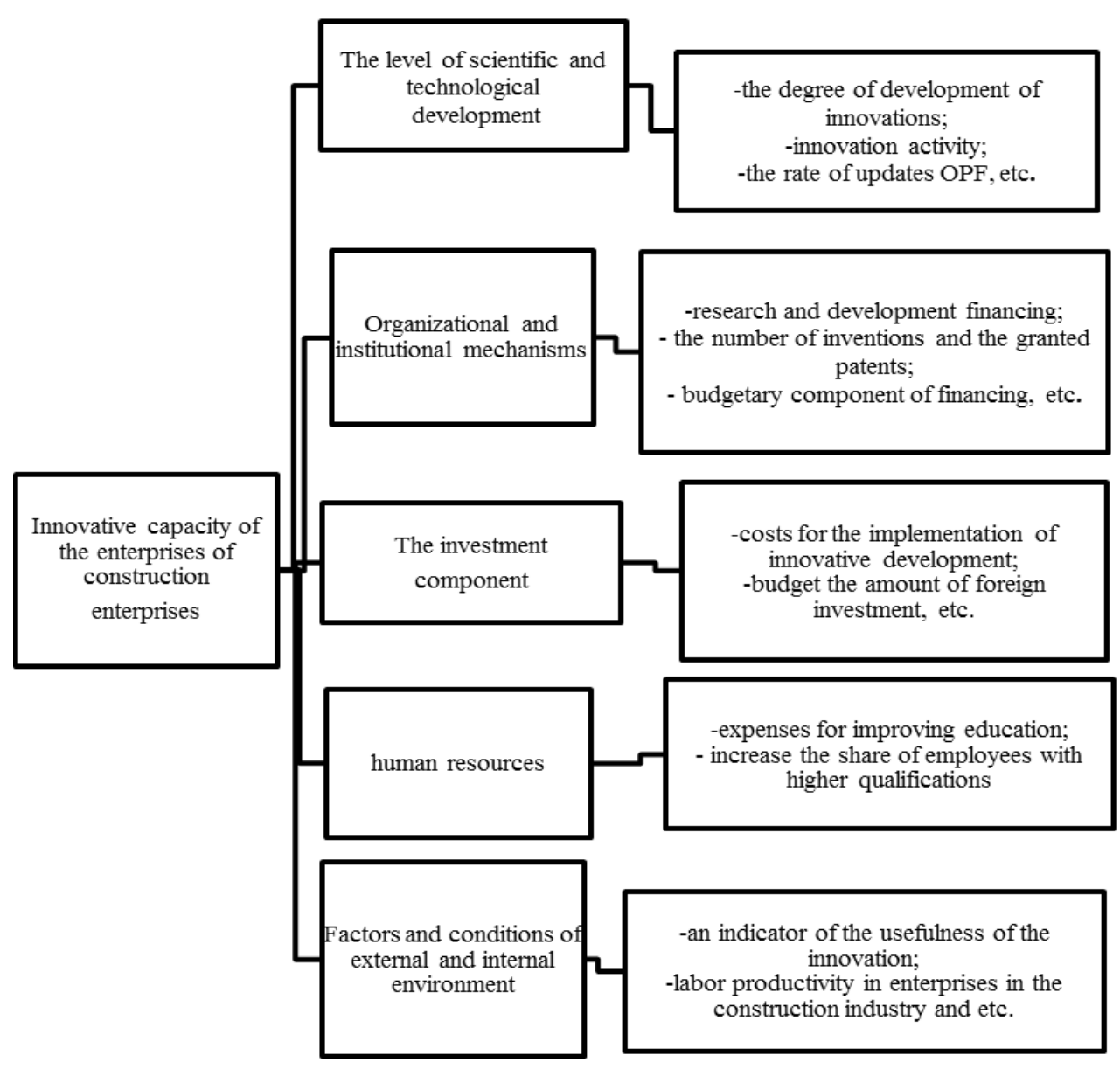

Fig. 1. The mechanism of formation of innovation potential of construction companies.

Based on the above, an important area of the innovation system in the industry production of building materials is to identify and encourage the development of regional cluster [24].

The role of the cluster in the development of innovation lies in the fact that within it formed stable relations between the participants of the production process, but also increases the proportion of competitive building materials produced by local construction companies, through the introduction of innovative methods in the organization of production (Fig. 2) [21,22]. 


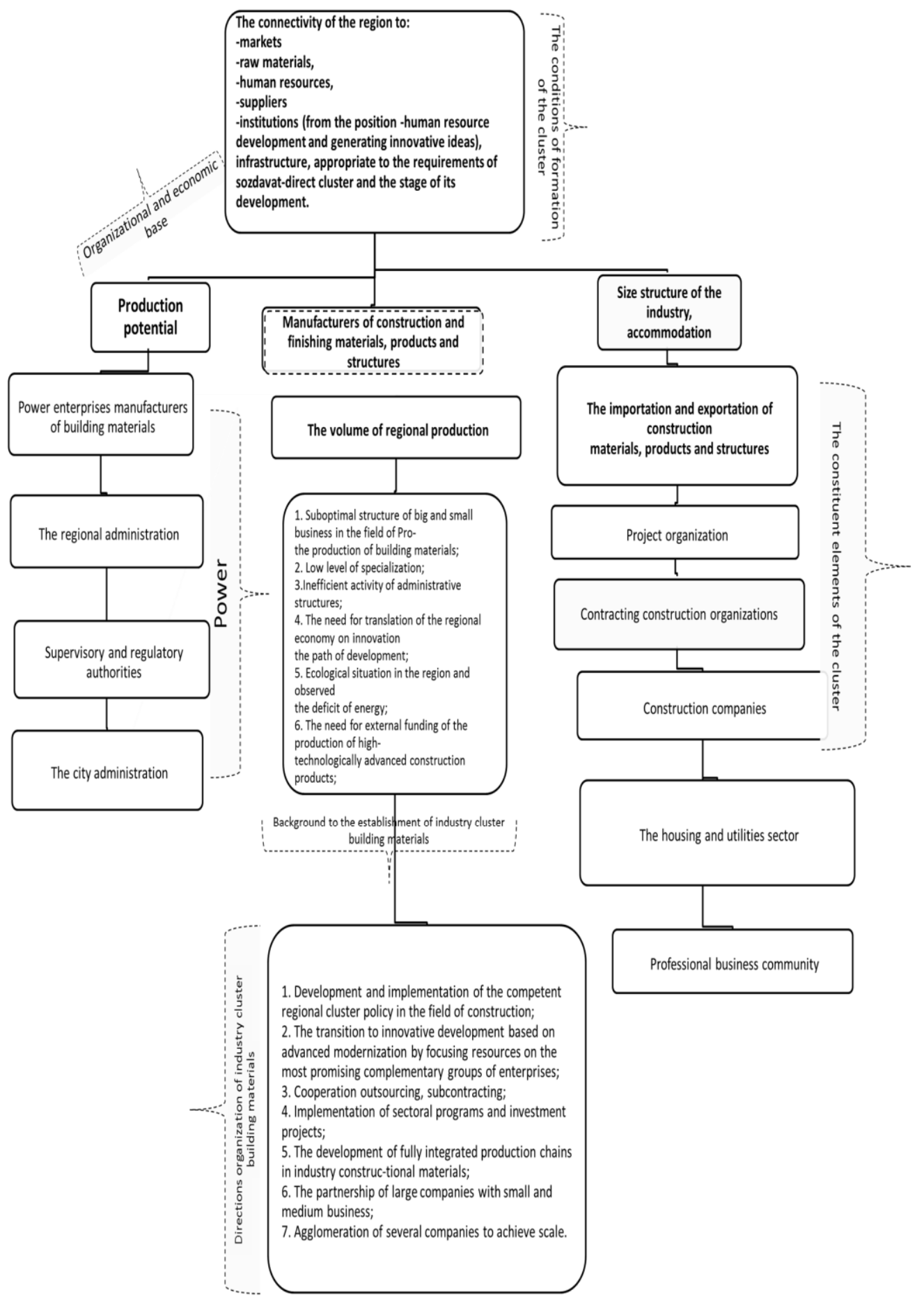

Fig. 2. The model of innovative development of building materials industry of the region based on the cluster approach. 
The most important mechanism for the spread of innovation in the regional production clusters is a partnership of large companies with small and medium-sized businesses. The mechanisms of this partnership are outsourcing, subcontracting, implementation of joint programs, market research, training and other activities. Besides, the companies involved in the cluster, can benefit from the fact that businesses operate near the same sector or group of production, even if they do not interact with the competitors and in the development of new products. The benefit is to reduce transaction and production costs, lowering the barrier to exit the marketing and supply of raw materials markets. With the support of the government is gradually going evolutionary process of the consolidation of the manufacturers on the conditions of cooperation - to develop a common policy on procurement of raw materials for production, output at the federal regional product and foreign markets and the creation of a unified distribution structure [23].

From an analytical point of view, referring to the cluster as an already established phenomenon, they have to be considered outside the usual production activities.

On the one hand, an association of companies that is located at a relatively compact area, which in itself provides the appearance of a synergistic effect. Between them there is a functional dependence in the production and sale of goods and services, competition and cooperation. They are focused on the production of a specific group of goods and at the same time focus on the development and production of innovative products.

On the other hand, is a cluster of informal education, uniting on a voluntary basis, the major leading companies, medium-sized and small companies, research and educational organizations. The complexity of the implementation of the cluster policy is that it is located at the junction of the industrial policy, economic and regional, under the responsibility of different ministries and departments, as no arms control industry sectors and industries, as it was under the planned economy, no longer exists. Despite this, the government plans to use various measures to support small and medium-sized businesses to promote cluster initiatives in the regions. In turn, the cluster approach gives regional authorities the tools of effective interaction with business, a better understanding of its characteristic parameters and tactical tasks and enables a focused and motivated strategic planning.

\section{Results}

The proposed mechanism of the organization of innovative development of the industry of building materials in the region based on the cluster will create conditions for:

- Formation and realization of competent regional cluster policy in the field of construction;

- Transition to innovative development based on advanced modernization by concentrating resources on the most promising complementary groups of companies;

- Cooperation, outsourcing, subcontracting;

- The implementation of sectoral programs and investment projects;

- The development of fully integrated process chains in the field of building materials industry;

- Partnerships with large companies to small and medium-sized businesses;

- Agglomeration of several construction companies to achieve scale.

Besides:

- Given the high potential of the construction industry in many areas and regions of Russia, which have well-developed industrial base, modern manufacturing facility, significantly surpassing their own needs in the region $(30 \%$ of the volume produced in the area of production is sold in other regions of the country), a rich mineral and raw material base, developed transport infrastructure - the proposed mechanism will generate the "points 
of growth" of innovative development of the industry production of building materials on the basis of the cluster;

- In terms of the number of research and training centers in the regions will create innovation cluster building materials industry with research and design centers, higher education institutions, as well as expand the number of participants in the cluster by the specialized innovative organizations - developers and technologist's production of innovative building materials. Also to introduce production technology and management innovations from other sectors of economic activity in the construction industry;

- Regional offices will be able to actively develop a new direction: the cooperation between small enterprises and major domestic manufacturers.

\section{Discussions}

Research shows that there is currently no uniform state policy on development of the industry of building materials, including innovation. Strategic approaches are presented only at the level of individual regions. In this regard, is it necessary to the formation of a strategic approach to the development of innovative building materials industry. Formation of a regional building cluster in a given situation will link industry with the development of the study of public policy priorities, as well as with those of other participants of the construction sector and with scientific basis.

However, analysis of the state of the industry in the context of the accession of the Russian Federation was held in the World Trade Organization has identified factors that may adversely affect the activities of enterprises and organizations of the industry of building materials production.

In the first place - is the lack of technical regulations and other regulatory documents governing the quality of products. In addition, there is no system of monitoring and state control of materials used in construction. And existing base of documents establishing the requirements to the characteristics of building materials and products requires a significant upgrade.

As a consequence, and also due to a lower level of regulatory requirements for quality construction materials produced in other countries, the regional construction market is projected delivery of large volumes of lower quality products, which will cause a decrease of quality of construction in the regions.

The arrival of the domestic construction market of imported technologies and materials will lead to a sharp decline in demand for products of Russian developers. The lack of market protection mechanisms and incomparably greater resources do not allow importing building materials, structures and locally produced products to compete with imported products.

Among sector problems include insufficient staff and management efficiency to ensure competitiveness, range of discrepancy, packaging, product certification requirements of world standards. And of course, the problem is the lack of available credit resources effective [19].

In addition, one of the reasons for lack of competitiveness of the industry is the lack of technological equipment with modern equipment such as industrial enterprises, as well as contractors. There are practically no production on the development and production of equipment for the creation of high-tech enterprises of the construction industry, modern means of transportation of materials [20, 24].

In this regard, today we need to be able to combine modern domestic design and research experience, and giving them official status, are clearly distinguished in separate directions in development. All this requires the regional authorities to carefully plan and carry out work on the development of innovative activity in the construction industry, 
which aims to create conditions for the transition to the current scenario of the entire regional economy. Since the need for a transition economy to an innovative way of development of the Russian Federation recognized as a major national task of the strategic nature of the Government, which will provide a solution to the translation of the economy to a higher technological way, and ultimately ensure its global competitiveness. For regions it is necessary to understand what industry, the formation of potential clusters and what they need to help them to become competitive on a global scale. This requires competent regional cluster policy.

\section{Conclusion}

It should be noted that in most regions of the development of the industry of building materials prevents the monopolization of regional construction markets, the organization of which has a local character. Competitive contracting companies provided their access to raw materials and production bases. As a rule, the main developers in the regions - a vertically integrated company, having in its structure a career, plants. A lack of competitive environment limits their motivation to optimize the cost of construction products.

For example, for the construction of 15-storey brick-monolithic houses in Russia requires a minimum of one and a half years, the complexity of the construction is not less than 500 thousand. Man-hr. This high cost. In China, there are examples where the building of 16 floors built in six days, time-consuming 27 thousand. Man-hours. Thus, virtually without using cement. This record delivered by advanced logistics, efficient organization of work at the site and the use of modern materials. The link between developers and manufacturers materials needs to be designers and architects, laying in the projects of modern materials and technology. To their use became widespread, we need projects that laid innovation [23].

The Russian construction market and construction materials industry is very unstable and very sensitive to external factors, market fluctuations. The main reason of instability in the inefficient organization of the value chain, and generally ineffective structure of the cost of production and services. [23]

To the traditional building materials industry to become one of the links in the global supply chain and not to lose not only engineering, but also domestic production, it is necessary to create an alternative construction industry on the basis of modern building science. Joining together in a cluster, it can carry out not only the construction companies, but also metallurgical concerns, organizing metal service centers and production of the metal, and logistics companies, providing a regular supply of materials, and other industries. In addition, for the active development of the construction industry in the region, the modernization of old and creation of new enterprises, increase production capacity, enterprises snap high-tech equipment necessary to stimulate the sector, attracting investment into it by government policy, as well as the activities of professional societies. This entire means that the region will be able to provide not only the construction of any facilities, but also to produce diverse class housing.

\section{References}

1. I. Ansoff, New corporate strategy: first (Peter Combe, SPb, 1999)

2. P.F. Drucker, Management Challenges in the XXI century ("Williams" Publishing House, 2000)

3. J. Schumpeter, The Theory of Economic Development (Progress, Moscow, 1982) 
4. B.Santo, B.V. Sazonov, Innovation as a tool for economic development: first. with Hung ( Progress, Moscow, 1990)

5. B. Twiss, Management of scientific and technical innovations: abbr. per. from English (Economics, Moscow, 1989)

6. C. Ketels, G.Lindqvist, O. Solvell, Stockholm:Center for strategy competitiveness, 42, (2006)

7. O. Solvell, Cluster balancing evolutionary and constructive forces - Odeshog: Danagards Grafiska (2009)

8. M. Porter, Competition: Per. from English ("Williams" Publishing House, M., 2000)

9. S. Goy, D.Finn, Energy Procedia, 78, 3391-3396 (2015)

10. F. J. Kaltsonetti, D. M. Miller, N. Reed, Applied Geography, 34, 265-273 (2012)

11. F. D. Doina, C. S. Badele, Social and Behavioral Sciences, 124, 405-414 (2014)

12. M. Khairullina, Procedia, 16, 88-94 (2014)

13. L.N. Asaul, Construction Economics, 6, 16-25 (2004)

14. A.V. Voronin, Regional economy: theory and practice, 16, 65-69 (2008)

15. I.M. Greenberg, Industrial and civil construction, 3, 25-27 (2006)

16. M. Casas, Industrial Economics of building materials and constructions (Publishing Association building universities, Moscow, 2004)

17. S. Kolyada, Building materials, 7, 4-8 (2008)

18. V.Y. Khmelev, Time, 1, 22-26 (2011)

19. Mr. Bogachev, Growing power of the construction industry Industrial Construction Review, 145, 49-52 (2012)

20. R. Mikhailov, Industrial and Construction Review, 138, 3-5 (2011)

21. L.S. Belousova, Sustainable development of a building complex in the region: monograph (Publishing house SPSUEF, SPb, 2010)

22. M.I. School, Organizational-economic mechanism of development of small preneurship in territorial investment-building complex: Abstract (Cand. e. Sciences, Volgograd, 2008)

23. D. Sanatov, The era of traditional construction industry comes to an end, But the Industrial and Construction Review, 137, 6-8 (2011)

24. A.B. Mottaeva, The methodology of the spatial distribution of business organizations in the region based on the development of transport infrastructure (2012)

25. S.V. Koshcheev, Herald of the Sochi State University for Tourism and Recreation, 1(15), 100-106 (2011)

26. I. Kuznetsov, Transport Russian business, 12(73), 62-67 (2009) 